\title{
STRATEGIES TO IMPROVE CYANINE DYE MULTI LAYER ORGANIC SOLAR CELLS
}

\author{
Roland Hany ${ }^{*}$, Bin Fan, Fernando Araujo de Castro $^{1}$, Jakob Heier, William Kylberg, and Frank Nüesch
}

Empa, Swiss Federal Laboratories for Material Science and Technology, Laboratory for Functional Polymers,

Überlandstr. 129, CH-8600 Dübendorf, Switzerland ; ${ }^{1}$ Present address: Materials Division, National Physical Laboratory, Hampton Rd, Teddington, Middlesex, UK, TW11 0LW; * roland.hany@empa.ch, phone: +41 448234084

\begin{abstract}
We report the status and strategies to improve the performance of cyanine dye / $\mathrm{C}_{60}$ bilayer heterojunction solar cells. Cyanines are characterized by convenience of synthesis and tunable light absorption. They have high light extinction coefficients, which offer the possibility to go around the constraints of small exciton diffusion length, and ultrathin films can be applied to fabricate multi layer organic solar cells. We optimized the cell performance by oxidative doping (with $\mathrm{O}_{2} /$ water/light, or $\mathrm{NOBF}_{4}$ ) of the cyanine layer. Doping increased the film conductivity and induced a steep rise in the short-circuit current and the open-circuit voltage. The external quantum efficiency approached $80 \%$ at maximum, meaning that the full cyanine layer of $30 \mathrm{~nm}$ thickness was active in charge generation. We argue that cyanine aggregates may be responsible for efficient charge transport over larger distances to the heterointerface. We also describe simple processes to match the energy to the low-lying hole-transporting cyanine level by using a thin organic salt layer or doped polyaniline as anode buffer layer. Thereby, hole injection was facilitated and good-performing devices (power conversion efficiency $\eta=3 \%$ ) with a high fill factor $(\mathrm{FF} \sim 60 \%$ ) were fabricated. Cyanine dyes are accompanied by mobile counter ions. These ions can diffuse into adjacent layers and build up important space charge that alters the energy levels at heterojunctions. The control of the ionic space charge allows to control the flow of electronic charge carriers and to implement new functionalities unique to organic opto-electronic devices.
\end{abstract}

Keywords: organic solar cell, cyanine dye, polyaniline

\section{INTRODUCTION}

Rapid progress is being made in the photovoltaic energy conversion using solution-processed organic semiconducting materials [1-3]. Polymers are leading the field, and power conversion efficiencies above $6 \%$ have been reported recently [4,5]. However, it has been recognized that small organic molecules possess some merits over polymers, such as ease of synthesis and purification, or high light absorption coefficients. Therefore, small molecule-based organic solar cells are receiving considerable research attention as well $[6,7]$.

Here, we report our recent work and discuss some research needs for the further improvement of cyanine dye / $\mathrm{C}_{60}$ solar cells. Cyanine dyes have initially been used for silver halide emulsion photography, and have recently attracted interest for biological, medical, laser and opto-electronic device applications.

In most cases, the organic solar cell components are coated from a common solvent, and phase separation between the electron donor and acceptor creates charge-separating heterojunctions throughout the material with dimensions within the exciton diffusion length of the active materials. However, the developing nanoscale blend morphology strongly depends on the processing conditions, and morphologies can be kinetically frozen in away from thermodynamical equilibrium. This is especially true for cyanines, that are actually organic salts and that are strongly incompatible with common apolar organic semiconducting materials [8]. This is one reason why our results were obtained for cyanine $/ \mathrm{C}_{60}$ cells fabricated in a simple bilayer configuration. Efficient planar, solution-processed organic heterojunction solar cells have been reported recently [9-11]. In a layered solar cell, the created charges are spatially separated and confined to the donor and acceptor site of the interface, and charge recombination is reduced. To avoid the exciton diffusion bottleneck, however, ultrathin dye films have to be applied, implying high light absorption coefficients and/or long exciton diffusion lengths; our results suggest that both of these conditions are met for cyanines.

\section{RESULTS AND DISCUSSION}

2.1 Cyanine dyes properties and solar cell design Figure 1a shows absorption spectra of thin films $(\sim 30-40 \mathrm{~nm})$ of typical cyanine dyes (Figure 1b) with increasing length of three (Cy3), five (Сy5) and seven (Cy7) methine groups. The absorption maxima is shifted to longer wavelength with increasing number of double bonds $(\sim 100 \mathrm{~nm}$ per additional methine group); therefore, a desired absorption range throughout the visible to the near-infrared region can simply be adjusted by synthesizing cyanines with the appropriate number of double bonds. The maximum absorption coefficients of these dyes are very high - Cy3: $\varepsilon($ DMSO, $553 \mathrm{~nm})=$ $140000 \mathrm{Lmol}^{-1} \mathrm{~cm}^{-1}$; Cy5: $\varepsilon(\mathrm{MeOH}, 680 \mathrm{~nm})=190000$ $\mathrm{Lmol}^{-1} \mathrm{~cm}^{-1}$; Cy7: $\varepsilon$ (DMSO, $\left.831 \mathrm{~nm}\right)=323000 \mathrm{Lmol}^{-}$ ${ }^{1} \mathrm{~cm}^{-1}$. Note that cyanines are charged cationic molecules and accompanied by a counter anion. Iodide usually results from the synthesis, but $\mathrm{I}^{-}$can be exchanged with other anions such as perchlorate or hexafluorophosphate; the cyanine dyes will be indicated accordingly (Cy3$\mathrm{ClO}_{4}, \mathrm{Cy} 3-\mathrm{PF}_{6}$, for example). The counter anion does not influence the optical properties of thin films (when coated from polar solvents [12]) and the redox energy levels of the cyanine chromophore. For $\mathrm{Cy} 3-\mathrm{ClO}_{4}$, we measured values for the field-effect carrier mobility $\mu \sim$ $10^{-6} \mathrm{~cm}^{2} \mathrm{~V}^{-1} \mathrm{~s}^{-1}$, and for the film conductivity under nitrogen atmosphere $\sigma=2.3 \cdot 10^{-5} \mathrm{Sm}^{-1}$.

Figure 1c shows the energy diagram of a cyanine dye $/ \mathrm{C}_{60}$ solar cell. A thin layer $(\sim 2.5 \mathrm{~nm})$ of tris-(8-hydroxyquinoline) aluminium $\left(\mathrm{Alq}_{3}\right)$ ensures Ohmic contact at the cathode, and poly(styrene sulfonate), (PSS), doped poly(3,4ethylenedioxythiophene), (PEDOT), or polyaniline 
(PANI) doped with dodecylbenzenesulfonic acid or PSS, were used as intermediate layers between the anode and the cyanine layer. PEDOT, PANI and the cyanine (usually dissolved in 3,3,4,4-tetrafluoropropanol) were spin coated from filtered solutions, $\mathrm{C}_{60}, \mathrm{Alq}_{3}$ and $\mathrm{Al}$ were deposited by thermal sublimation under vacuum. All device measurements were performed under inert atmosphere. We note that cyanine dyes are stable molecules, and when kept in the dark, can be stored at ambient conditions for years. Fabricated solar cells were also stable over several days (for doped devices) and weeks (for undoped devices) in the glovebox, but true lifetime data are not yet available.

a)

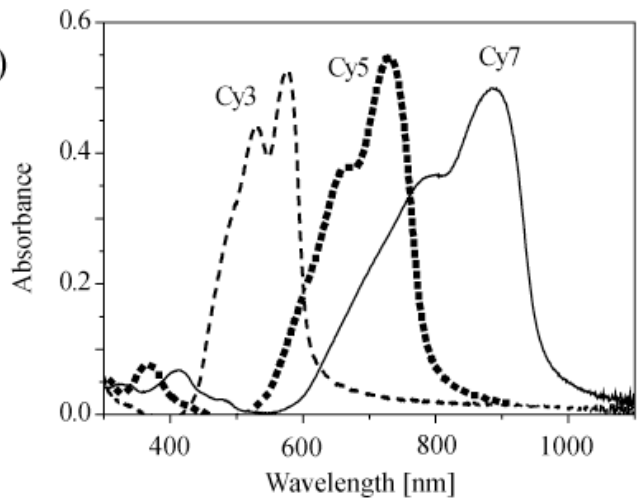

b)

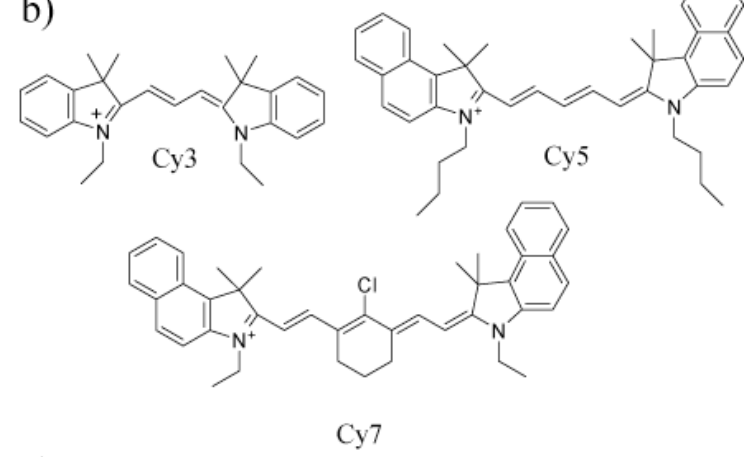

c)

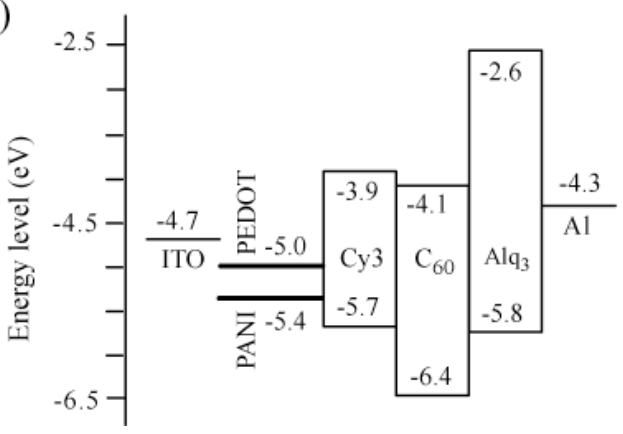

Figure 1: a) Thin film absorbance spectra and (b) molecular structures of cyanine dyes with increasing number of $\mathrm{sp}^{2}$ carbon atoms forming the $\pi$-conjungated bridge between electron-donating and -accepting groups. The associated cyanine counter anions are omitted. c) Energy levels of the frontier molecular orbitals relative to the vacuum level.

\subsection{Status of cyanine dye / $\mathrm{C}_{60}$ solar cell performance} In earlier work, we found that cyanines can act both as electron donor and acceptor in organic solar cells, demonstrated that cyanine counter anions can be displaced in an electric field, and tried to use cyanines in bulk heterojunction devices [8,13-15]. However, performances of these initial devices were low, and an asfabricated ITO/PEDOT/Cy3/ $\mathrm{C}_{60} / \mathrm{Al}$ solar cell yielded approximate values of $\mathrm{I}_{\mathrm{sc}} \sim 1 \mathrm{mAcm}^{-2}$ for the short-circuit current, $\mathrm{V}_{\mathrm{oc}} \sim 0.3 \mathrm{~V}$ for the open-circuit voltage, $\mathrm{FF} \sim$ 0.18 for the fill factor, and an efficiency $\eta \sim 0.05 \%$ (light intensity $100 \mathrm{mWcm}^{-2}$ ).
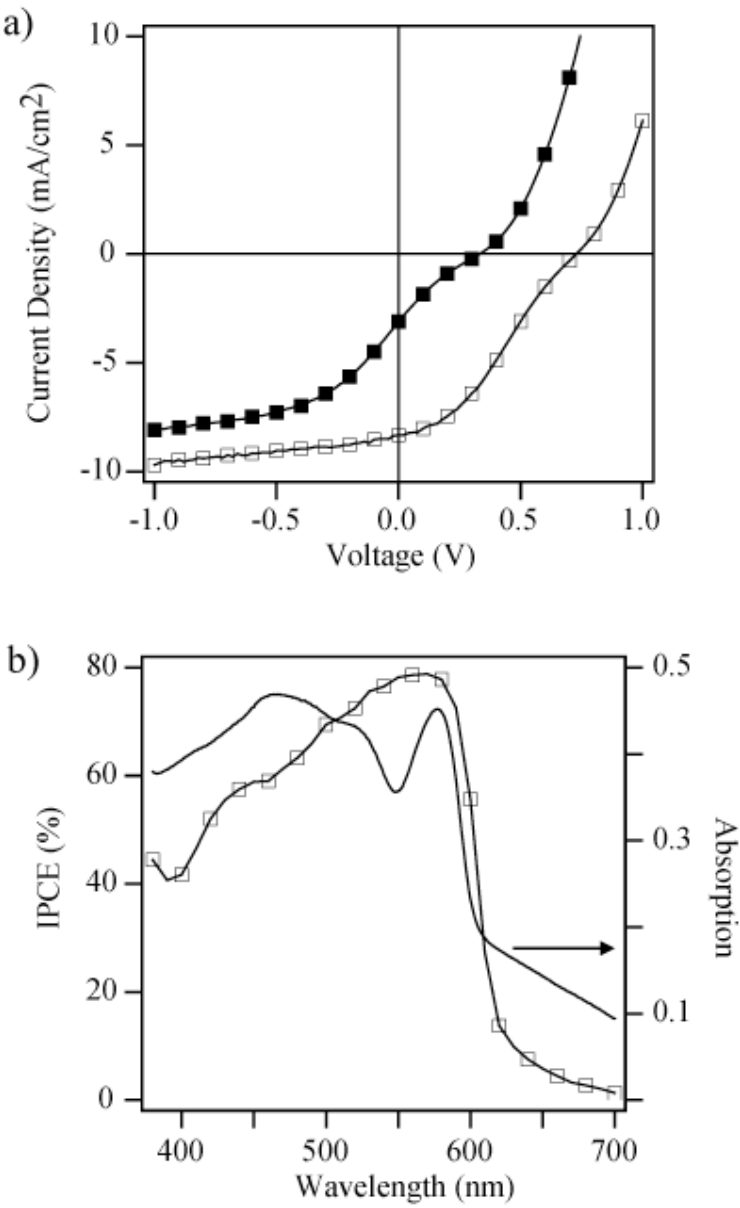

Figure 2: Performance of ITO/PEDOT(40 nm)/Cy3$\mathrm{ClO}_{4}(30 \mathrm{~nm}) / \mathrm{C}_{60}(40 \mathrm{~nm}) / \mathrm{Alq}_{3}(2 \mathrm{~nm}) / \mathrm{Al}(60 \mathrm{~nm})$ solar cells with and without $\mathrm{NOBF}_{4}$ doping. a) Current-voltage characteristics for the undoped (full squares) and doped cell (open squares) at $100 \mathrm{mWcm}^{-2}$ AM1.5 simulated solar irradiation. $\mathrm{I}_{\mathrm{sc}}=8.3 \mathrm{mAcm}^{-2}, \mathrm{~V}_{\mathrm{oc}}=0.72 \mathrm{~V}, \mathrm{FF}=$ $0.34, \eta=2 \%$ were measured for the doped cell. b) Corresponding IPCE curve of the doped cell and device absorption spectrum. The $\mathrm{NOBF}_{4}$ doping concentration was $0.02 \mathrm{~mol} / \mathrm{mol} \mathrm{Cy} 3-\mathrm{ClO}_{4}$.

Much-improved performances were obtained by oxidative doping of the cyanine layer. For the doping chemicals iodine and $\mathrm{XeF}_{2}$, a pronounced increase in $\mathrm{I}_{\mathrm{sc}}$ was observed; however, devices were not stable, probably due to chemical side reactions. Photoinduced oxygen doping in ambient air involving water vapour formed a rectifying barrier at the anode, and performance values increased substantially $\left(\mathrm{I}_{\mathrm{sc}}=1.83 \mathrm{mAcm}^{-2}, \mathrm{~V}_{\mathrm{oc}}=\right.$ $0.73, \mathrm{FF}=0.27, \eta=1.2 \%, 30 \mathrm{mWcm}^{-2}$ ) [16]. The best doping chemical so far has been $\mathrm{NOBF}_{4}$ (Figure 2) [17]. The merit of this doping agent is that the cyanine can be 
oxidized in solution in a controlled way. Concentrated $\mathrm{NOBF}_{4}$ stock solutions were first produced in acetonitrile where the $\mathrm{NO}^{+}$cation is stable for several hours. Aliquots of the stock solution were then added to a $\mathrm{Cy} 3-\mathrm{ClO}_{4}$ solution in chlorobenzene and used for spin coating smooth doped films.

Oxidative doping at the chemical level means charge transfer from the cyanine to an electron acceptor, accompanied by the insertion of a counter ion that ensures charge neutrality for the whole system. We attribute the marked increase in performance upon doping to a combination of two effects. First, doping increased the conductivity of the cyanine films $[16,17]$. This lowers the series resistance limitation encountered in the clean film, improves the hole transport through the donor layer and results in increased short-circuit current and fill factor. Second, doping improved the charge injection contact between PEDOT and the cyanine layer. When the PEDOT is in contact with the doped cyanine dye, charge will flow across the heterojunction from the PEDOT to the organic material, so as to equalize the Fermi levels. The presence of a net negative charge density extending into the cyanine layer will create an electric field, with the corresponding potential inducing a band-like bending of the energy levels in the vicinity of the junction. As a consequence, the hole charge collection is facilitated, and the effective anode work function and the open-circuit voltage are increased (Figure 2a).

The doping results clearly demonstrated the inefficient hole transfer across the unmodified PEDOT/Cy3 interface. Indeed, the energy gap between the HOMO energy levels of PEDOT and the cyanine dye is rather large $(>0.5 \mathrm{eV}$, Figure $1 \mathrm{c})$, potentially resulting in unfavourable hole transfer kinetics. It is expected, therefore, that by lowering the energy barrier at the anode, the hole transfer is facilitated, resulting in more balanced charge collection and an increase in the fill factor and the open-circuit voltage [18].

In one example, we modified the anode work function with a dipole layer (Figure 3). For this purpose, a thin salt layer was sandwiched between PEDOT and the cyanine layer. The arrangement of molecules and charges created an internal electrical field and resulted in an increase of the respective work function. Thereby, the energy offset for hole extraction was reduced and the cell efficiency increased. It is interesting to compare the short-circuit currents of the salt-treated (Figure 3) and the best-performing doped solar cells (Figure 2). These currents are rather similar $\left(\mathrm{I}_{\mathrm{sc}}=7.5\right.$ vs. $8.3 \mathrm{mAcm}^{-2}$, respectively), implying that the proper energy level matching at the anode/cyanine dye interface is essential for improved performance, and that the hole transport in the untreated cyanine bulk layer is probably not a devicelimiting factor.

In another example, we used doped polyaniline (PANI) layers as interface materials between ITO and the cyanine layer [19]. The work function of PANI $(\sim-5.4$ $\mathrm{eV})$ is substantially higher than the work function of PEDOT $(\sim-5 \mathrm{eV})$, (Figure 1c), and the energy offset at the anode/cyanine interface is importantly reduced. Best results so far were achieved when using PANI doped with dodecylbenzenesulfonic acid, and for an ITO/PANI $(30 \mathrm{~nm}) / \mathrm{Cy} 3-\mathrm{PF}_{6}(30 \mathrm{~nm}) / \mathrm{C}_{60}(40 \mathrm{~nm}) / \mathrm{Alq}_{3}(2.5 \mathrm{~nm}) / \mathrm{Al}$ $(60 \mathrm{~nm})$ solar cell, $\mathrm{I}_{\mathrm{sc}}=-6.92 \mathrm{mAcm}^{-2}, \mathrm{~V}_{\mathrm{oc}}=0.72 \mathrm{~V}, \mathrm{FF}$ $=0.61, \eta=3.0 \%$ was measured. This is one of the highest performances achieved with solution-processed small molecules so far. Balanced charge extraction and an ohmic or near-ohmic contact at the anode by replacing PEDOT with the high-work function PANI layer was also supported by constant values for the fill factor (at FF $\sim 0.6$ ) when varying the white light intensity.

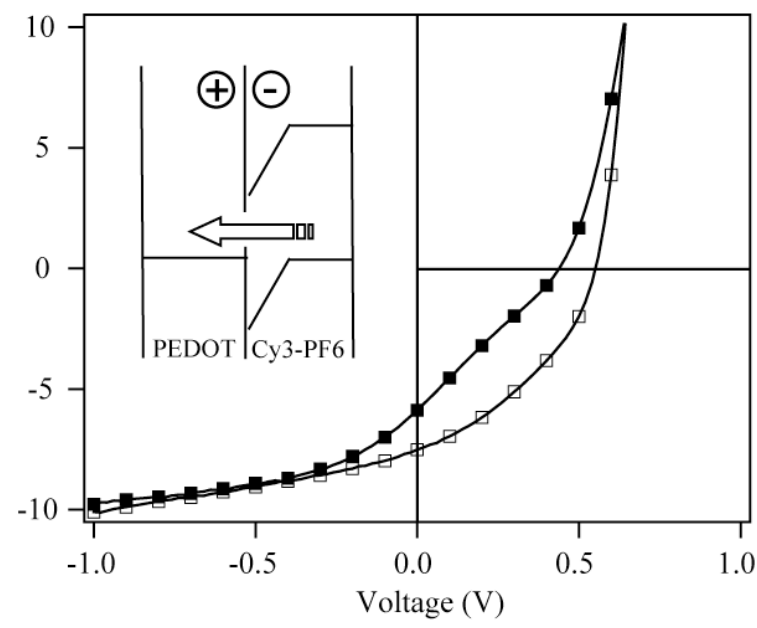

Figure 3: I-V characteristics of ITO/PEDOT/Cy3- $\mathrm{PF}_{6}(30$ $\mathrm{nm}) / \mathrm{C}_{60} / \mathrm{Alq}_{3} / \mathrm{Al}$ solar cells without (filled squares) and with (open squares) an intermediate layer of $\mathrm{NH}_{4}^{+} \mathrm{BF}_{4}^{-}$ (plus, minus signs in schematic). Open squares: $\mathrm{I}_{\mathrm{sc}}=7.51$ $\mathrm{mAcm}^{-2}, \mathrm{~V}_{\mathrm{oc}}=0.56 \mathrm{~V}, \mathrm{FF}=0.38, \eta=1.6 \%$.

2.3 Research needs for cyanine dye solar cell improvement

The use of cyanine mixtures to extend the light absorption over the visible to the near-infrared range (Figure 1) or the combination of doping and energy matching at the anode in one cell concept are obvious approaches for the further improvement of cyanine dye solar cells. In addition, the possible role of cyanine aggregates in the charge generation process and the pronounced influence of the type of counter anion on cell performance need to be addressed in detail.

\subsubsection{The possible role of cyanine dye aggregates}

As shown in Figure $2 b$, the IPCE of the $\mathrm{NOBF}_{4}$-doped cell reaches a maximum value of nearly $80 \%$ at $580 \mathrm{~nm}$. This is a high value considering the solar cell absorbance of 0.47 at this wavelength. In a simple picture, $89 \%$ of the incident light is absorbed by the cyanine layer, when the light is reflected at the aluminium back electrode and travels twice through the cell. It follows that essentially every absorbed photon is separated in a charge pair at the cyanine / $\mathrm{C}_{60}$ heterojunction and that all charge carriers are collected at the electrodes. This means that the full cyanine layer has to be active in the charge generation process. We found that the IPCE rapidly decreased for thicker cyanine films (IPCE $=55 \%$ for $35 \mathrm{~nm}$ cyanine film) [17].

These results imply an apparent cyanine exciton diffusion length in the order of the film thickness of 30 $\mathrm{nm}$, which is a high value, compared to the typical 5-10 $\mathrm{nm}$ that photoexcited states in polymeric semiconducting materials are able to diffuse. Possibly, the heterojunction interface is not sharp and the evaporated $\mathrm{C}_{60}$ molecules diffuse substantially into the dye, leading to an extended 
zone in the cyanine layer where exciton dissociation and charge generation occurs [20]. As a second possibility, we consider that cyanine dye dimer / aggregates may be responsible for efficient charge transport to the heterointerface. Cyanine dyes can self-assemble into highly ordered two- or three-dimensional structures consisting of thousands of molecules [21]. The photoexcited state is extended over the entire aggregate, and results in exciting optical phenomena such as fast energy migration, very narrow and strong light absorption, resonance fluorescence or superquenching [22].
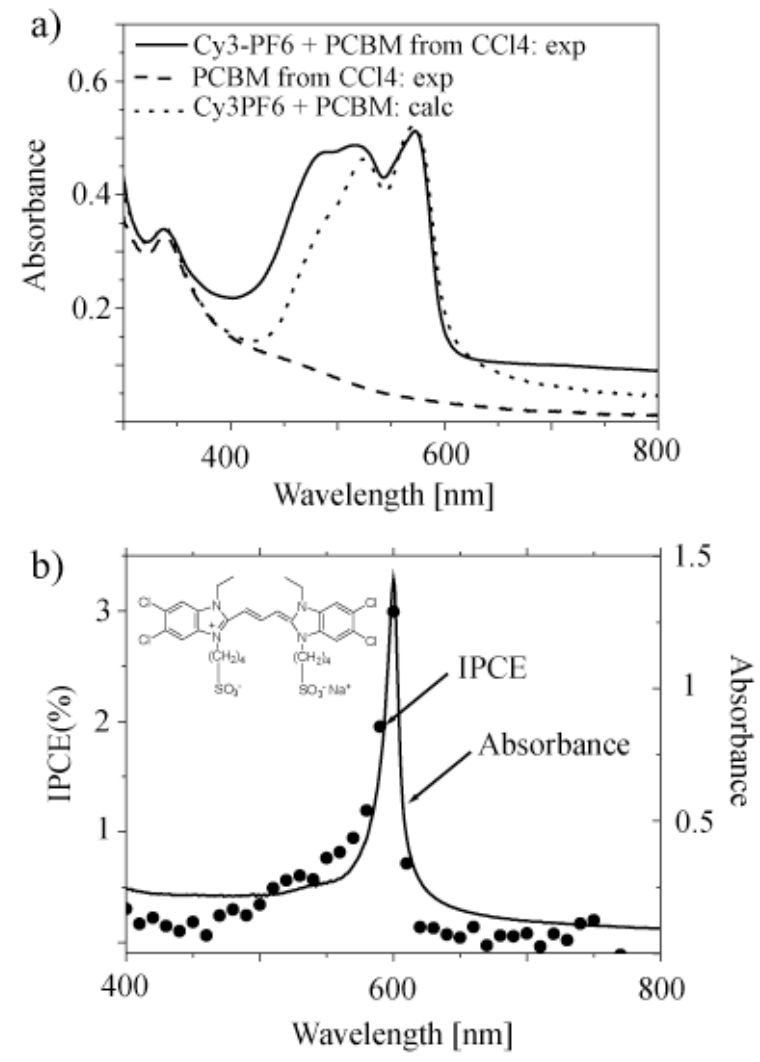

Figure 4: a) Absorption spectra demonstrating the $\mathrm{PCBM}$-induced $\mathrm{H}$-aggregate formation in $\mathrm{Cy} 3-\mathrm{PF}_{6}$ films. Spin coating a PCBM solution on top of the cyanine layer results in a spectrum (solid line) different from the calculated superposition (dotted line) of a pure PCBM (dashed line) and Cy3- $\mathrm{PF}_{6}$ spectrum (see Figure 1a). The additional absorbance features in the wavelength region between $450 \mathrm{~nm}$ and $500 \mathrm{~nm}$ are assigned to cyanine $\mathrm{H}$ aggregates. b) Absorbance spectrum and IPCE response of an ITO/PANI/cyanine/Al solar cell. This cyanine dye easily forms J-aggregates with a strong absorbance peak at $\sim 600 \mathrm{~nm}$.

Depending on the stacking angle between cyanine molecules, H-aggregates with a blue-shifted absorption compared to the monomer, or J-aggregates with a red-shifted absorption are formed. Referring to Figure 1a, the cyanine dye film absorption spectra are characterized by intense monomer absorptions at long wavelengths, and broad and smaller dimer absorption bands at shorter wavelengths [23]. In all three cyanine dye spectra, an additional small blue-shifted shoulder is visible that can be ascribed to $\mathrm{H}$-aggregates.

We carried out transient absorption spectroscopy on pure cyanine films [24]. Bleaching signals were observed over a wavelength domain corresponding to the absorption spectrum of the dye. In addition, a positive absorbance change was observed at shorter wavelengths. This transient absorbance signal appeared within the duration of the laser pulse, and its decay with a slow kinetics was mirrored by the recovery of the ground state absorption. The transient absorbance was assigned to the cyanine radical dication, since oxidized states of cyanine dyes are typically characterized by blue-shifted absorption spectra with regard to the ground state absorption [17].

In continuous wave fluorescence spectroscopy [24], pure cyanine films were only weakly emissive, and the photoluminesence increased by up to three orders of magnitude when the cyanine was dispersed into an inert polymer matrix of polystyrene. These results suggest an efficient self-quenching mechanism of photoexcited cyanines as the dye molecules pack closer with increasing concentration. We speculated that cyanine dimer / $\mathrm{H}-$ aggregate formation possibly accounts for the selfquenching [24], and these anionic cyanine species could transport generated charge over larger distances to the cyanine / $\mathrm{C}_{60}$ heterojunction.

Usually, cyanine dye aggregates form in lowconcentrated aqueous solutions, which is unsuitable for organic opto-electronic device applications. In Figure 4a, we demonstrate that $\mathrm{H}$-aggregates can also be grown from organic solvents. When coating a $\mathrm{CCl}_{4}$ solution of [6,6]-phenyl $\mathrm{C}_{61}$-butyric acid methyl ester (PCBM) on a Cy3- $\mathrm{PF}_{6}$ layer, the absorption in the 450-500 nm wavelength region characteristic for $\mathrm{H}$-aggregates is importantly increased. Note that $\mathrm{CCl}_{4}$ alone does not induce aggregation, and the presence of PCBM is essential. We developed a general method to induce molecular order in cyanine dyes from organic solvents using PCBM by self-assembly [23]. H-aggregates nucleate on PCBM subcluster surfaces within a porous PCBM domain, and these $\mathrm{H}$-aggregates can be rearranged into J-aggregates [25]. In ongoing work we try to further control the cyanine dye self-assembly process, collect and characterize these aggregates, and correlate solar cell performance with their occurrence. Also, the importance of energy transfer processes of excited cyanine monomers to aggregates needs to be studied. As a preliminary example, Figure $4 \mathrm{~b}$ shows a cyanine film absorption spectrum that is dominated by a very narrow J-aggregate peak at $600 \mathrm{~nm}$. The IPCE follows the absorption, demonstrating that light absorption by the $\mathrm{J}$ aggregates produces photocurrent.

\subsubsection{The influence of cyanine dye counter anions}

The existence of counter anions that balance the positive charge of the dye chromophore is a special characteristic of cyanines. We have demonstrated [14] that these anions are relatively mobile and are displaced into adjacent layers, either by diffusion due to concentration gradients or by internal or applied external electrical fields. The build-up of ionic space charge creates internal electric fields and induces potential energy shifts at heterojunctions similar to conventional inorganic $\mathrm{p}-\mathrm{n}$ junctions. 
In one illustrative example, we used a $\mathrm{Cy} 5-\mathrm{Cl} /$ $\mathrm{C}_{60}$ heterojunction to demonstrate that $\mathrm{C}_{60}$ can be converted into an electron donor [26]. In this case, the small and mobile chloride distributed to a large extent throughout the fullerene layer, and the associated ionic charge density and interfacial potential shift raised the lowest unoccupied energy level (LUMO) of $\mathrm{C}_{60}$ above the LUMO level of the cyanine.

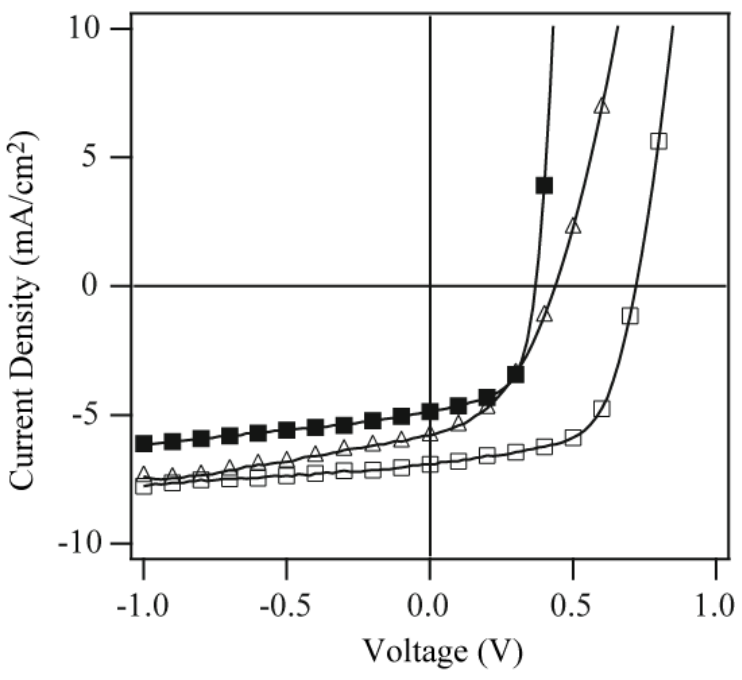

Figure 5: I-V characteristics of ITO/PANI/Cy3/ $\mathrm{C}_{60} / \mathrm{Alq}_{3} / \mathrm{Al}$ solar cells with the counter ions $\mathrm{ClO}_{4}^{-}$(filled squares), $\mathrm{PF}_{6}^{-}$(open squares), and $\mathrm{PF}_{6}^{-}$(triangles) after applying a bias of $+2 \mathrm{~V}$ for 1 minute.

Figure 5 demonstrates another example of the distinct influence of the type of counter anion on solar cell performance. For as-fabricated devices, $\mathrm{Cy} 3-\mathrm{PF}_{6}$ performs much better than $\mathrm{Cy} 3-\mathrm{ClO}_{4}$. By applying a positive external bias to the $\mathrm{Cy} 3-\mathrm{PF}_{6}$ cell, however, the open-circuit values became rather similar. The initial performance was restored after allowing for a relaxation time of several hours or by applying a negative bias. We ascribe these effects due to the difference of anionic displacement across the electrode and organic / cyanine heterointerface. The ionic radius and specific chemical affinites determine the extent and distance the anions diffuse away from the cyanine layer and the final distribution determines the slope of energy level shifts. Mobile ions also screen electronic charges leading to reduced electron-hole pair recombination at the heterojunction or can build up space charge that creates a field opposite to the direction of generated charge out of the device. Therefore, the analytics to determine the presence and concentration of anions in organic thin films is an important necessity for the further improvement of ionic organic opto-electronic devices.

\section{CONCLUSION}

Cyanine dye / $\mathrm{C}_{60}$ heterojunction solar cells with an efficiency of $3 \%$ can now be produced. The planar bilayer cell structure avoids the need for tedious control of the blend film morphology and simplifies the investigation of related dyes. Energy level matching at the anode / cyanine interface was the most important step for device improvement so far, and we suspect that reducing the energy gap for hole extraction might result in improved device efficiencies for a number of other material systems based on polymers and small molecules with low-lying redox levels as well. Considering the rather narrow absorption band of the $\mathrm{Cy} 3$ dye, further improvement should be possible by using a cyanine mixture to absorb a greater fraction of the light irradiation. The role of aggregates as light-harvesting antennas is under discussion [27] and needs to be exploited for cyanine dye solar cells. The control of ionic space charge that builds up due to mobile anions is an important research need, and we anticipate that innovative chemistry [28] to permanently fix such ionic junctions will add exciting new functionalities to cyanine-based opto-electronic devices.

\section{ACKNOWLEDGEMENTS}

The Swiss Competence Center for Energy and Mobility CCEM-CH, "swisselectric research" and the Swiss Federal Office of Energy (BFE) are gratefully acknowledged for their financial support. We thank R. Steiger for helpful discussions.

\section{REFERENCES}

[1] Lloyd MT, Anthony JE, Malliaras GG. Mater. Today 2007; 10: 34-41.

[2] Hoppe H, Sariciftci NS. J. Mater. Res. 2004; 19: 1924-1945.

[3] Kippelen B, Brédas J-L. Energy Environ. Sci. 2009; 2: 251-261.

[4] Park SH, Roy A, Beaupré S, Cho S, Coates N, Moon JS, Moses D, Leclerc M, Lee K, Heeger AJ. Nature Photon. 2009; 3: 297-303.

[5] Liang Y, Xu Z, Xia J, Tsai ST, Wu Y, Li G, Ray C, Yu L. Adv. Mater. 2010; 22: 1-4.

[6] Bürckstümmer H, Kronenberg NM, Gsänger M, Stolte M, Meerholz K, Würthner F. J. Mater. Chem. 2010; 20: 240-243.

[7] Silvestri F, Irwin MD, Beverina L, Facchetti A, Pagani GA, Marks TJ. J. Am. Chem. Soc. 2008; 130: 17640-17641.

[8] Castro FA, Faes A, Geiger T, Graeff CFO, Nagel M, Nüesch F, Hany R. Syn. Metals 2006; 156: $973-978$.

[9] Alam MM, Jenekhe SA. Chem. Mater. 2004; 16: 4647-4656.

[10] Perez MD, Borek C, Djurovich PI, Mayo EI, Lunt RR, Forrest SR, Thompson ME. $A d v$. Mater. 2009; 21: 1517-1520.

[11] Ma B, Woo CH, Miyamoto Y, Fréchet JMJ. Chem. Mater. 2009; 21: 1413-1417.

[12] Bouit PA, Aronica C, Toupet L, Guennic BL, Andraud C, Maury O. J. Am. Chem. Soc. 2010; 132: 4328-4335.

[13] Meng F, Chen K, Tian H, Zuppiroli L, Nüesch F. Appl. Phys. Lett. 2003; 82: 3788-3790.

[14] Nüesch F, Faes A, Zuppiroli L, Meng F, Chen K, Tian H. J. Mater. Sci. 2005; 40: 1353-1357.

[15] Nüesch F, Tornare G, Zuppiroli L, Meng F, Chen K, Tian H. Solar Energy Mater. Solar Cells 2005; 87: 817-824. 
[16] Fan B, Hany R, Moser JE, Nüesch F. Org. Electronics 2008; 9: 85-94.

[17] Fan B, Castro FA, Heier J, Hany R, Nüesch F. Org. Electronics 2010; 11: 583-588.

[18] Steim R, Kogler FR, Brabec CJ. J. Mater. Chem. 2010; 20: 2499-2512.

[19] Fan B, Castro FA, Chu BTT, Heier J, Opris D, Hany R, Nüesch F. J. Mater. Chem. 2010; 20: 2952-2955.

[20] Markov DE, Amsterdam E, Blom PWM, Sieval AB, Hummelen JC. J. Phys. Chem. A 2005; 109: $5266-5274$

[21] Eisele DM, Knoester J, Kirstein S, Rabe JP, Vanden Bout DA. Nature Nanotech. 2009; 4: 658-663.

[22] Spano FC. Acc. Chem. Res. 2010; 43: 429-439.

[23] Heier J, Steiger R, Nüesch F, Hany R. Langmuir 2010; 26: 3955-3961.

[24] Castro FA, Benmansour H, Moser JE, Graeff CFO, Nüesch F, Hany R. Phys. Chem. Chem. Phys. 2009; 11: 8886-8894.

[25] Steiger R, Pugin R, Heier J. Colloids and Surfaces B 2009; 74: 484-491.

[26] Benmansour H, Castro FA, Nagel M, Heier J, Hany R, Nüesch F. Chimia 2007; 61: 787-791.

[27] Das S, Kamat PV. J. Phys. Chem. B 1999; 103: 209-215.

[28] Hoven CV, Wang H, Elbing M, Garner L, Winkelhaus D, Bazan GC. Nature Mater. 2010; 9: 249-252. 